See Article page 157.

\section{Commentary: If you start me up...I may never stop?}

\author{
Tomasz A. Timek, MD, PhD
}

Permanent pacemaker (PPM) insertion is a well-recognized complication of valvular surgery, with an incidence of $4 \%$ $51 \%$ depending on the type and number of valves replaced and surgical versus transcatheter approach ${ }^{1,2}$ Although device insertion is needed for chronotropic support of cardiac function, the long-term complications of paced physiology and device-related morbidities are still being examined. Some studies suggest decreased long-term survival with postoperative PPM insertion, ${ }^{3,4}$ whereas others do not confirm these trends. A propensity-matched analysis of more than 24,000 patients from the Taiwan National Insurance Research Database ${ }^{5}$ revealed that PPM implantation may affect long-term mortality based on the site of valve surgery or combination of implanted valves. Furthermore, pacemaker dependency after device implantation may also play an important role in distant survival. ${ }^{6}$ The work by Bianco and colleagues ${ }^{7}$ from the University of Pittsburgh presented in the current issue of the Journal adds valuable data to this controversy and suggests that when adjusted for patient characteristics, PPM implantation after isolated valve or valve and coronary surgery does not affect distal survival. Although the authors present a large clinical cohort, the results and conclusions of the study need to be evaluated through a prism of several methodologic limitations.

Right ventricular pacing has been shown to lead to pacing-induced heart disease, adverse remodeling, and heart failure, ${ }^{8}$ with clinical consequence usually seen after

\footnotetext{
From the Division of Cardiothoracic Surgery, Spectrum Health, Grand Rapids, and Michigan State University College of Human Medicine, East Lansing, Mich. Disclosures: The author reported no conflicts of interest.

The Journal policy requires editors and reviewers to disclose conflicts of interest and to decline handling or reviewing manuscripts for which they may have a conflict of interest. The editors and reviewers of this article have no conflicts of interest.

Received for publication July 18, 2021; revisions received July 18, 2021; accepted for publication July 19, 2021; available ahead of print Aug 26, 2021.

Address for reprints: Tomasz A. Timek, MD, PhD, Division of Cardiothoracic Surgery, Spectrum Health, 100 Michigan Ave NE, Grand Rapids, MI 49503 (E-mail: tomasz.timek@spectrumhealth.org).

JTCVS Open 2021;7:165-6

2666-2736

Copyright (C) 2021 The Authors. Published by Elsevier Inc. on behalf of The American Association for Thoracic Surgery. This is an open access article under the CC BY-NCND license (http://creativecommons.org/licenses/by-nc-nd/4.0/).

https://doi.org/10.1016/j.xjon.2021.07.020
}

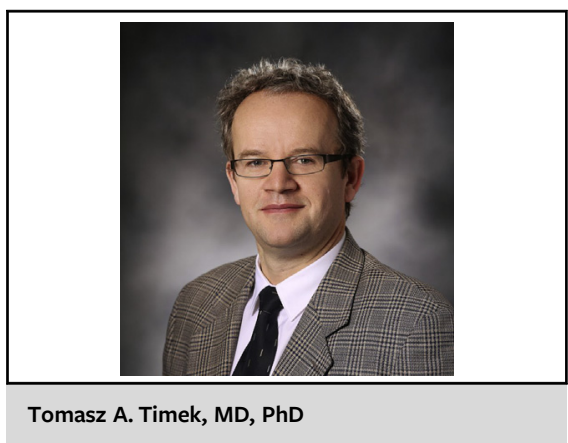

CENTRAL MESSAGE

Pacemaker implantation after

cardiac surgery may not inde-

pendently affect 5-year survival.

more than 3 years of ventricular pacing. ${ }^{9}$ Similarly, the rate of device-related complications such as lead fracture or endocarditis accumulate over time, resulting in up to $10 \%$ of all implanted leads needing eventual replacement. Data from a US Extraction Database reported a 1.4\% major complication rate in an extraction of 3540 leads at a mean of $47 \pm 41$ months after implantation..$^{10}$ The follow-up in the current study extends mostly up to 5 years from time of operation and therefore may not fully capture the morbidity and potential mortality associated with PPM in the long term. In the current study, neither the rate of pacemaker infection nor lead replacement was reported. A similarly sized study from the Mayo Clinic of PPM implantation after aortic valve replacement with a median follow-up of 11.1 years revealed that device implantation was associated with increased risk of death even after multivariate adjustment of baseline patient characteristics. ${ }^{3}$ Indeed, in the adjusted analysis, the survival curves appeared to diverge more clearly after 5 years. The conclusion of the study by Bianco and colleagues hinges on a risk-adjusted population, but although the investigators present a large clinical cohort, propensity matching was not feasible and hence adjustment for baseline characteristics, although statistically rigorous, incomplete. The authors enrolled only patients with aortic or mitral valve procedure, and no double- or triple-valve surgeries were included. However, these more complex patients have greater risk profiles and rates of PPM implantation, which may further exacerbate baseline ventricular dysfunction and congestive symptoms. As such, extrapolation of the current data to all-encompassing valve surgery should be approached with restraint. Rhythm disturbances are a rare but real consequence of valvular surgery that are unlikely to be 
mitigated by percutaneous techniques. ${ }^{2}$ Surgical teaching dictates that nothing is without consequence, and the need for a pacing device implantation after valve procedures should be viewed through the same lens for both surgical and transcatheter valve approaches. How consequential of a procedure PPM implantation will become, only time and rigorous follow-up will demonstrate.

\section{References}

1. Robich MP, Schiltz NK, Johnston DR, Mick S, Krishnaswamy A, Iglesias RA, et al. Risk factors and outcomes of patients requiring a permanent pacemaker after aortic valve replacement in the United States. J Card Surg. 2016;31: 476-85.

2. Siontis G, Jüni P, Pilgrim T, Stortecky S, Büllesfeld L, Meier B, et al. Predictors of permanent pacemaker implantation in patients with severe aortic stenosis undergoing TAVR: a meta-analysis. J Am Coll Cardiol. 2014;64: 129-40.

3. Greason KL, Lahr BD, Stulak JM, Cha YM, Rea RF, Schaff HV, et al. Long-term mortality effect of early pacemaker implantation after surgical aortic valve replacement. Ann Thorac Surg. 2017;104:1259-64.
4. Mehaffey JH, Haywood NS, Hawkins RB, Kern JA, Teman NR, Kron IL, et al. Need for permanent pacemaker after surgical aortic valve replacement reduces long-term survival. Ann Thorac Surg. 2018;106:460-5.

5. Chi MC, Hung KC, Chang SH, Chien-Chia W, Chou AH, Chan YH, et al. Effect of permanent pacemaker implantation after valve surgery on long-term outcomes. Circ J. 2021;85:1027-34.

6. Lorusso R, Ravaux JM, Barili F, Bidar E, Vernooy K, Mauro MD, et al. Relation of prolonged pacemaker dependency after cardiac surgery to mortality. GIROC Investigators. Am J Cardiol. 2021;138:66-71.

7. Bianco V, Kilic A, Aranda-Michel E, Serna-Gallegos D, Dunn-Lewis C, Chen S, et al. Permanent pacemaker placement following valve surgery is not independently associated with worse outcomes. J Thorac Cardiovasc Surg Open. 2021;7:157-64.

8. Elder DH, Lang CC, Choy AM. Pacing-induced heart disease: understanding the pathophysiology and improving outcomes. Expert Rev Cardiovasc Ther. 2011;9: 877-86.

9. Urena M, Rodés-Cabau J. Permanent pacemaker implantation following transcatheter aortic valve replacement: still a concern? JACC Cardiovasc Interv. 2015;8:70-3.

10. Byrd CL, Wilkoff BL, Love CJ, Sellers TD, Turk KT, Reeves R, et al. Intravascular extraction of problematic or infected permanent pacemaker leads: 19941996. U.S. Extraction Database, MED Institute. Pacing Clin Electrophysiol. 1999;22:1348-57. 